\title{
ANÁLISE DOS GRÃOS DE PÓLEN DE DIFERENTES CULTIVARES DE MANONA (RICINUS COMMUNIS L., EUPHORBIACEAE): CONSERVAÇÃO E VIABILIDADE*
}

\author{
D.P. Vargas ${ }^{1}$, S.A.M. Souza ${ }^{2}$, S.D. Anjos e Silva ${ }^{3}$, V.L. Bobrowski ${ }^{4}$ \\ ${ }^{1}$ Universidade Federal de Lavras, Departamento de Biologia, Laboratório de Cultura de Tecidos em Plantas, \\ CP 37, CEP 37200-000, Lavras, MG, Brasil. E-mail: dvbio@hotmail.com
}

\section{RESUMO}

\begin{abstract}
A análise da fertilidade dos grãos de pólen de Ricinus communis (mamona) é de grande importância para programas de melhoramento, permitindo o manejo e uso adequado das coleções existentes e a criação de cultivares interessantes na produção de biodiesel. Neste trabalho, optou-se por um processo preditivo baseado no método citológico de coloração dos grãos de pólen e no método de germinação in vitro dos grãos, após tratamentos de conservação a baixas temperaturas, para a verificação da viabilidade, importante na formação das sementes, alvo dos programas de melhoramento. Utilizou-se a técnica de coloração com carmim acético $2 \%$ na análise da viabilidade dos grãos de pólen nas cultivares IAC-80, Cafelista, AL-Preta e AL-Guarany 2002, enquanto que o método de germinação in vitro após tratamento de $-196^{\circ} \mathrm{C},-80^{\circ} \mathrm{C} \mathrm{e}-18^{\circ} \mathrm{C}$, por 15 e 30 dias, foi aplicado somente na cultivar IAC-80. A viabilidade polínica foi acima de $95 \%$ em IAC-80 e Cafelista de 88,48\% em AL-Preta e de 86,46\% em e AL-Guarany 2002. Estas cultivares apresentaram também alto percentual de viabilidade polínica na antese, sendo possível a utilização de todas as cultivares analisadas na indução de fertilização em programas de melhoramento. Os resultados obtidos com a germinação in vitro dos grãos de IAC-80, após a criopreservação, indicaram que o percentual médio da viabilidade polínica in vivo não foi influenciado pelo período de armazenamento. Observaram-se diferenças entre os tratamentos a baixas temperaturas, porém o percentual de viabilidade dos mesmos foi baixo, sugerindo necessidade de adequação na técnica de avaliação.
\end{abstract}

PALAVRAS-CHAVE: Ricinus communis L., mamona, grãos de pólen, carmin-acético, melhoramento genético, crioconservação.

\begin{abstract}
POLLEN GRAIN ANALYSIS OF SOME CULTIVARS OF CASTOR-OIL PLANT (RICINUS COMMUNIS L., EUPHORBIACEAE): CONSERVATION AND VIABILITY. The analysis of the pollen grain fertility of Riccinus communis (castor-oil plant) is of great importance for breeding programs, allowing for suitable handling and use of collections and the creation of cultivars of interest for biodiesel production. In this work, a predictive process was chosen based on the cytological method of pollen-grain staining and in-vitro pollen germination after low-temperature treatments for preservation to verify the pollen viability, which is important in seed fertilization and formation. The conventional cytological staining technique with $2 \%$ acetic carmine was used for pollen grain viability analysis for the cultivars IAC-80, Cafelista, AL-Preta and AL-Guarany 2002 , while the method of in-vitro germination after treatment at $-196^{\circ} \mathrm{C},-80^{\circ} \mathrm{C}$ and $-18^{\circ} \mathrm{C}$, from 15 to 30 days, was used for the cultivar IAC-80. The IAC-80 and Cafelista cultivars showed pollen viability values above 95\%, while AL-Preta and AL-Guarany 2002 showed 88.48 and $86.46 \%$, respectively. The pollen grains of castor-oil cultivars also presented a high percentage of pollen viability at anthesis. Therefore, it is possible to use the pollen grains of all the analyzed cultivars for fertilization induction in breeding programs. The results indicate that the average percentage
\end{abstract}

${ }^{2}$ Universidade Estadual do Norte Fluminense, Laboratório de Melhoramento Genético Vegetal, Campos de Goytacazes, RJ, Brasil.

${ }^{3}$ EMBRAPA-Centro de Pesquisa Agropecuária de Clima Temperado, Pelotas, RS, Brasil.

${ }^{4}$ Universidade Federal de Pelotas, Instituto de Biologia, Pelotas, RS, Brasil.

*Parte da dissertação de mestrado da primeira autora. 
of the pollen-grain viability in-vivo was not influenced by the storage period. It was also observed that there were differences among the low-temperature treatments, although the percentage of viability was low, suggesting the need for the application of a suitable evaluation technique.

KEY WORDS: Ricinus communis L., castor-oil, pollen grain, plant breeding, cryopreservation.

A mamona (Ricinus communis L.) pertence à família Euphorbiaceae que inclui um grande número de espécies nativas da região tropical. É também chamada carrapateira, baforeira e baga. Planta de hábito arbustivo, com diversas colorações de caule, folhas e frutos, podendo apresentar cera no caule e pecíolo. A inflorescência é do tipo panícula racemosa e terminal (cacho), de 15 a $50 \mathrm{~cm}$ de comprimento, com as flores dispostas em rácemos terminais, sendo que as femininas ocupam a parte superior enquanto que as masculinas a parte inferior do eixo da inflorescência e as hermafroditas em posição intermediária (LORENZI; MATOS, 2002; AzEvedo et al., 1997; Sousa et al., 2004). Os frutos, geralmente, apresentam espinhos e as sementes, ricas em óleos graxos ricinoléicos, podem ter diferentes tamanhos, formatos e grande variabilidade de coloração (LoREnZI; MATOS, 2002; AMORIM Neto et al., 2001; Azevedo et al., 1997, SAvi FilHo, 2005). O óleo da mamona é utilizado para vários processos industriais tais como na fabricação de desinfetantes, óleos lubrificantes, tintas e corantes, servindo ainda de base para a composição de fungicidas, inseticidas, na fabricação do náilon e da matéria plástica, cujo emprego é importantíssimo na composição de velas e revestimento de embalagens (Figueiredo Neto et al., 2004). É também uma alternativa promissora na produção de biodiesel (Sousa et al., 2004).

Acultura da mamona tem considerável potencial para a economia do País, principalmente nas regiões doSemi-árido, pois resiste a longos períodos de seca, além de favorecer as questões de mão-de-obra e produção de matéria prima para diversas aplicações industriais (АмоRIM Neto et al., 2001).

De acordo com Sousa et al (2004), a Índia, a China, o Brasil e a antiga União Soviética são os maiores produtores de mamona, sendo que em 1995/1996 cerca de $90 \%$ da produção mundial da safra foi atribuída aos três primeiros países. O Brasil foi, há algumas décadas, o maior produtor mundial de mamona e o maior exportador do óleo. Na safra de 1974 foram produzidas aproximadamente 573.000 t de mamona; já em 1996, a produção nacional foi de apenas $122.000 \mathrm{t}$, o que representa uma redução de 79\% (Almeida et al., 2002).

A busca por novas variedades mais produtivas inclui técnicas de cruzamentos entre plantas que, muitas vezes, diferem na sazonalidade e, para tanto, o armazenamento, transporte emanutenção de pólen com alta viabilidade são importantes (CUCHIARA et al., 2007).
A viabilidade do grão de pólen, em geral, diminui gradualmente com o tempo reduzindo a eficiência da fertilização. De acordo com Sousa et al. (2004), o período de viabilidade do pólen fresco de mamona é de aproximadamente uma semana, restringindo testes de polinização controlada, de procedência e de progênie, a fim de gerar materiais genéticos melhorados. Para possibilitar tais cruzamentos, há a necessidade de se dispor, prontamente, de pólen viável armazenado (SousA-LANG; PINTO, 1997). A conservação dos grãos de pólen é, portanto, de grande importância para a preservação da variabilidade genética além de facilitar o intercâmbio de germoplasma, contribuir significativamente na geração de variabilidade obtida através de cruzamentos artificiais e aumentar a eficiência dos programas de melhoramento (GoMEs et al., 2003).

O método de criopreservação de grãos de pólen, em nitrogênio líquido $\left(-196^{\circ} \mathrm{C}\right)$, surgiu como um método eficiente. Pesquisas recentes vêm estabelecendo protocolos para o armazenamento de grãos de pólen de várias espécies de importância econômica (Parton, 2001 apud Silva et al., 2000). A técnica da crioconser-vação reduz o metabolismo a níveis tão baixos que todos os processos bioquímicos são significativamente reduzidos e a deterioração biológica é virtualmente paralisada. Algumas das vantagens da crioconservação são o pequeno espaço a ser ocupado por um banco de germoplasma, a simplicidade de manuseio das condições de armazenamento e por fim o baixo custo do processo (Almeida et al., 2002). No entanto, a grande dificuldade do processo está no impedimento da formação de cristais de gelo no interior das células, os quais podem causar ruptura das membranas resultando em colapso e morte celular (SANTOS et al., 2002; SALOMOM, 2003).

A estimativa da viabilidade dos grãos de pólen frescos ou fixados, e dos criopreservados, pode ser feita através do emprego de diferentes técnicas sendo que as mais utilizadas são a coloração do citoplasma dos grãos e a germinação in vitro, esta última muito empregada no monitoramento de pólen vivo armazenado (Oliveira et al., 2001).

O objetivo deste trabalho foi avaliar a viabilidade dos grãos de pólen de mamona (Ricinus communis L.) quando submetidos a baixas temperaturas de armazenamento e a possibilidade de seu uso em programas de melhoramento da cultura, contribuindo para a seleção de variedades e a criação de cultivares tendo em vista a produção de sementes para a extração de óleos. 
Foram utilizadas as cultivares IAC-80, Cafelista, AL-Preta e AL-Guarany 2002, todas provenientes do campo experimental da Embrapa Clima Temperado, localizado em Pelotas, RS, na latitude $31^{\circ} 41^{\prime}$ Sul e longitude $52^{\circ} 21^{\prime}$ Oeste e altitude de $60 \mathrm{~m}$.

As amostras foram coletadas, emjunho de 2005, de três inflorescências em estádios de desenvolvimento diferentes, levadas ao laboratório e mantidas em água destilada à temperatura ambiente até a abertura floral. Para a análise da conservação polínica, a mistura de pólen das inflorescências foi coletada e acondicionada em minitubos de 2,0 mL.

\section{Crioconservação do pólen da cv. IAC-80}

Os tratamentos de crioconservação utilizados neste experimento restringiram-se inicialmente à cultivar IAC-80 e foram: (a) em nitrogênio líquido $\left(-196^{\circ} \mathrm{C}\right),(\mathrm{b})$ ultrafreezer $\left(-80^{\circ} \mathrm{C}\right) \mathrm{e}(\mathrm{c})$ freezer $\left(-18^{\circ} \mathrm{C}\right)$, por 15 e 30 dias. Foi também efetuada a germinação direta, ou seja, semeadura dos grãos de pólen em lâminas escavadas contendo meio de cultura logo após a coleta, como controle da viabilidade polínica inicial para todos os tratamentos.

\section{Teste de viabilidade do pólen das cultivares}

Botões florais masculinos das quatro cultivares estudadas e com aproximadamente $6,0 \mathrm{~mm}$ de diâmetro foram coletados, por já apresentarem deiscência e formação de pólen estabelecida. Foram fixados em Carnoy 3:1 (álcool etílico: ácido acético, respectivamente) por 2 a 24 horas e, posteriormente, transferidos para freezer a $-10^{\circ} \mathrm{C}$. Para preparo das lâminas utilizou-se hidrólise das anteras por cerca de 10 minutos em $\mathrm{HCl} 5 \mathrm{~N}$, a $25^{\circ} \mathrm{C}$, logo em seguida, as anteras foram maceradas em carmim acético $2 \%$, e o material recoberto com lamínula para posterior análise.

Os grãos de pólen corados com o carmim acético foram analisados eclassificados emnormais/viáveis, com citoplasma corado e anormais/inviáveis, aqueles com pouco ou nenhum citoplasma evidenciado (GuERRA; SOUZA, 2002). Considerou-se oito repetições de 250 células/lâmina por cultivar, totalizando 2000 células analisadas.

A comparação de médias foi realizada através do teste de Duncan a 5\% de probabilidade (ZONTA; MACHADO, 1984).

Além deste método rápido e tradicional de estimativa da viabilidade, foi empregado também o teste da germinação in vitro, para os grãos da cv. IAC-80 submetidos aos tratamentos a frio, bem como o controle. Utilizou-se o meio de cultura de acordo com a metodologia descrita por GOMEs (1998) contendoágar $(0,8 \%)$ e sacarose $(10 \%)$. As lâminas foram colocadas em câmara úmida e incubadas por 24 horas a $25 \pm 1^{\circ}$
C, sendo considerados viáveis aqueles que haviam emitido tubo polínico.

Foi utilizado o delineamento inteiramente casualizado, com oito repetições de 250 grãos de pólen totalizando 2.000 grãos de pólen analisados.

A análise da variância foi realizada utilizando-se o programa estatístico SANEST (ZONTA; MACHADO, 1984). Os dados, expressos em percentagem, foram transformados segundo arco seno da raiz quadrada de $X / 100$, onde $X$ representa o valor percentual obtido para cada variável.

\section{Viabilidade polínica das cultivares}

A viabilidade polínica das cultivares avaliadas, através do método de coloração por carmim acético de grãos de pólen coletados e fixados foi superior a $86 \%$ (Tabela 1), e considerada alta, pois de acordo com Souza et al. (2002), em maracujá, e Domingues et al. (1999), em laranja, valores acima de 70\% representam alta viabilidade, de 31 a $69 \%$ média e até $30 \%$ baixos índices de viabilidade. Observou-se também queas porcentagens médias para as cultivares IAC-80 e Cafelista (96,71 e 95,73\%, respectivamente) foram superiores às demais, diferindo significativamente a $5 \%$ das outras cultivares AL-Preta e AL-Guarany 2002, com médias de 88,48 e $86,46 \%$, respectivamente.

A ocorrência de diferenças na viabilidade de pólen entre diferentes plantas da mesma variedade ou cultivares, ou ainda entre diferentes épocas de coleta, tem sido relatada por alguns pesquisadores, porém a maior e mais significativa variação tem ocorrido entre genótipos diferentes (LogUercio; BATtistin, 2004). Resultados similares a estes foram observados neste experimento, haja vista que todas as cultivares apresentaram um alto índice de viabilidade, embora seconsidere que o método da estimativa comouso do corante superestime a porcentagem de germinação do pólen, enquanto que o teste in vitro a subestime (GALETTA, 1983).

Tabela 1 - Percentual de viabilidade polínica de cultivares de mamona Ricinus communis L das cultivares: IAC-80, Cafelista, AL-Preta e AL-Guarany 2002, com o uso carmim-acético em grãos de pólen fixados.

\begin{tabular}{lc}
\hline $\begin{array}{c}\text { Cultivares de } \\
\text { Ricinus communis }\end{array}$ & $\begin{array}{c}\text { Médias de } \\
\text { viabilidade polínica* }\end{array}$ \\
\hline IAC-80 & $96.71^{\mathrm{a}}$ \\
Cafelista & $95.73^{\mathrm{a}}$ \\
AL-Preta & $88.48^{\mathrm{b}}$ \\
AL-Guarany 2002 & $86.46^{\mathrm{b}}$
\end{tabular}

*Médias seguidas por letras diferentes diferem entre si pelo teste de Duncan a $5 \%$ de probabilidade. C.V. $=5,39 \%$. 
De acordo com Loguercio; BATTISTIN (2004), através de estudos sobre a viabilidade polínica pode-se estimar o potencial de reprodução de uma espécie, cultivar ou população. Segundo ainda LOGUERCIO; BATTISTIN (2004), muitas angiospermas produzem elevado percentual de pólen viável, muito embora nem todos possam ser utilizados na fertilização efetivamente. Considerando-se que a manifestação do genótipo de um indivíduoéo resultado da contribuição trazida pelos gametas masculino e feminino, quanto maior a viabilidade polínica, maior a possibilidade da formação de diferentes combinações entre alelos, isto é, aumento de variabilidade genética a qual é imprescindível para a seleção de novos cultivares com características agronômicas desejáveis (SouZAet al., 2002). Portanto os resultados obtidos neste estudo indicam serem estas cultivares viáveis para utilização em programas de melhoramento (Tabela 1).

DOMINGUES et al. (1999), comparando a técnica da coloração de pólen com carmim acético a $25 \%$ com os trabalhos de Moreira e Gurgel (apud LoGUerCIO; BAtTistin, 2004) que utilizaram carmim acético $40 \%$, descreveram que, mesmo em concentrações menores do corante, esta metodologia permite boas análises de viabilidade do pólen e que as concentrações maiores permitem apenas fotos mais nítidas. Estes dados corroboram com aqueles obtidos neste experimento utilizandocarmimacético $2 \%$ para pólen demamona, pois permitiu uma boa distinção entre pólens viáveis einviáveis considerando esta metodologia adequada para avaliação de viabilidade polínica (Fig. 1).

O efeito do ambiente no comportamento meiótico, e conseqüentemente na viabilidade dos grãos de pólen, foi observado por Souza (2002) em Passiflora edulis sugerindo que variações na temperatura ambiental podem interferir na microsporogênese, microgame-togênesee, conseqüentemente, na viabilidade dos grãos, diminuindo a formação de frutos e de sementes. De acordo com estes dados é possível que a alta viabilidade encontrada nos genótipos estudados indique uma adaptabilidade da mamona às condições ambientais da região sul do Brasil.

\section{Crioconservação dos grãos de pólen}

Verificou-se através da análise de variância que houve diferenças altamente significativas para os tratamentos avaliados, indicados pela diferença na germinação do pólen (Tabela 2). Dentre os tratamentos, aquele que apresentou melhor índice de germinação de pólen foi o ultrafreezer $\left(-80^{\circ} \mathrm{C}\right)$, podendo ser considerado o mais eficiente entre os sistemas testados (Tabela 2). Não foi verificada diferença significativa quanto à viabilidade dos grãos conservados por 15 e por 30 dias na mesma temperatura de tratamento, indicando que os pólens após o congelamento inicial poderão ficar por um longo período mantendo a mesma viabilidade (Tabela 2). Diferentemente dos resultados obtidos por PEREIRA et al. (2002) onde, em experimentos com pólens de várias espécies de eucalipto (Eucalyptus sp.), foram evidenciadas diferenças na viabilidade associadas com o tempo de armazenamento. Conforme ainda esses mesmos autores, o período de quatro meses para a estocagem de pólen de eucalipto é mais do que suficiente para dar maior flexibilidade às atividades de hibridação dos programas de melhoramento.

A redução do potencial de germinação dos grãos de pólen submetidos aos tratamentos pode ter ocorrido devido ao congelamento do líquido celular, causando o rompimento da membrana e da parede celular dos grãos (Fig. 2A) ou a liberação de exudatos do líquido interno (Fig. 2B). Observou-se, porém, que em pólens de mamona onde aparentemente ocorreu a liberação de exudato ocorreu também a germinação (Fig. 2C).

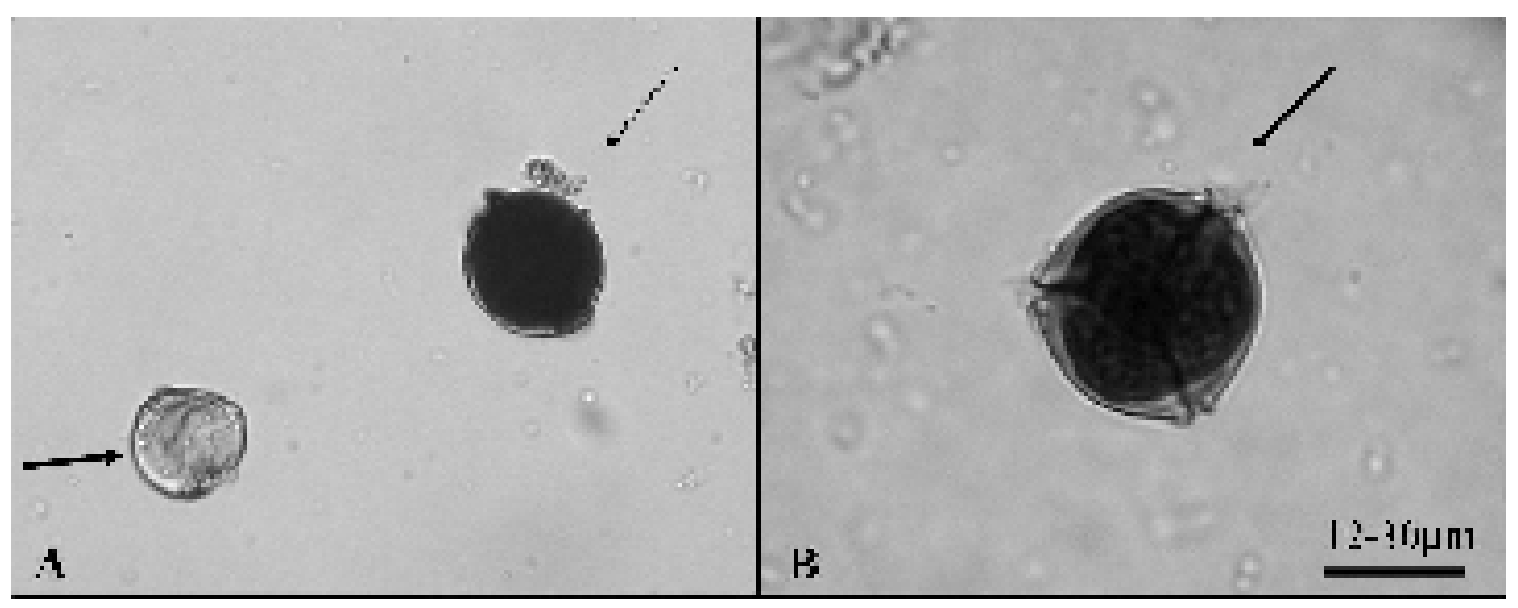

Fig. 1 - Grãos de pólen após coloração com carmim acético. (A) viável (seta pontilhada) e inviável (seta cheia). (B) Pólen viável, observando-se o contorno da exina e intina e a abertura dos poros de forma bem definida (seta). 

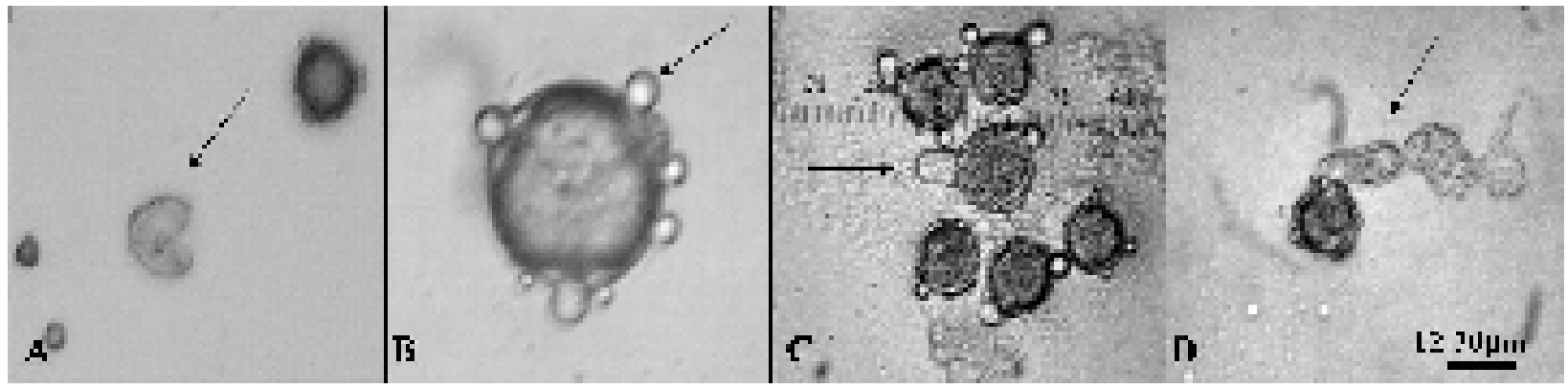

Fig. 2 -Grãos de pólen de mamona Ricinus communis var. IAC-80 após crioconservação. (A) Pólen rompido ao lado de pólen viável. (B) Pólen não germinado com exsudato; (C) grãos de pólen mostrando detalhe na germinação (seta). (D) Pólen germinado e com liberação de exsudato submetidos ao congelamento a $-80^{\circ} \mathrm{C}$ por uma hora.

Em cultivares de maracujazeiro os grãos de pólen parecem estar recobertos pelo pollenkit que, dentre outras funções, atua como protetor, minimizando a desidratação e conseqüentemente a perda de viabilidade nesta espécie (Souza et al., 2002), Na Figura 2D, observa-se a liberação de uma sustância que pode estar relacionada a cobertura externa do grão de pólen.

O baixo índice de viabilidade no controle pode ser conseqüência da qualidade da amostra, a algum pequeno distúrbio na meiose, embora esta não tenha sido estudada no presente trabalho, ou pode ainda ser decorrente da manipulação dos grãos na execução da técnica utilizada na análise.

Deve-se considerar também, de acordo com experimentos com diversas espécies e cultivares, a variação no tempo de germinação dos grãos, sugerindo a necessidade de estudos complementares que estabeleçam um tempo ideal de germinação para cada cultivar de mamona estudada, e para a espécie. Em Eucalyptus calmadulensis, por exemplo, a germinação é mais rápida que outras espécies do mesmo gênero (Pereira. et al., 2002).

Embora fique evidente a eficiência da técnica de armazenamento por criopreservação, para outras espécies, os resultados deste trabalho sugerem que o armazenamento de pólen para as cultivares de mamona estudadas requer ainda adaptações no processo.

Os grãos de pólen de mamona apresentaram alto percentual de viabilidade polínica na antese pelo método de estimativa com o corante carmim acético, ocorrendo variações neste percentual em relação às cultivares estudadas.

O meio básico utilizado para avaliação da germinação in vitro de pólen de mamona após tratamentos a baixas temperaturas parece não ter sido adequado, pois foi observado um baixo percentual de germinação em todos os tratamentos inclusive no controle, contrapondo-se à estimativa de viabilidade por corante que excedeu $90 \%$.

Para conservação da viabilidade polínica, dentre as diferentes temperaturas testadas, o uso de ultrafreezer $\left(-80^{\circ} \mathrm{C}\right)$ foi o mais eficiente.
Tabela 2 - Percentual médio de germinação dos grãos de pólen de mamona cv. IAC-80, submetidos a baixas temperaturas e em dois períodos de armazenamento.

\begin{tabular}{llll}
\hline Tratamentos & Médias* $^{*} 15$ Dias & 30 \\
dias & & & \\
Controle & $12,70^{\mathrm{a}}$ & $12,70^{\mathrm{a}} 12,70^{\mathrm{a}}$ & \\
Ultrafreezer $-80^{\circ} \mathrm{C}$ & $0,82^{\mathrm{b}}$ & $0,52^{\mathrm{a}} 1,19^{\mathrm{a}}$ \\
Freezer $-18^{\circ} \mathrm{C}$ & $0,04^{\mathrm{c}}$ & $0,00^{\mathrm{a}}$ & $0,19^{\mathrm{a}}$ \\
\hline Nitrogênio líquido $-196^{\circ} \mathrm{C}$ & $0,08^{\mathrm{c}}$ & $0,09^{\mathrm{a}}$ & $0,00^{\mathrm{a}}$
\end{tabular}

${ }^{*}$ Médias seguidas por letras diferentes diferem entre si pelo teste de Duncan a 5\% de probabilidade.

\section{AGRADECIMENTOS}

Ao pesquisador Dr. Sérgio Delmar dos Anjos e Silva. Ao Centro de Pesquisa Agropecuária Clima Temperado, EMBRAPA-RS. À CAPES pela bolsa concedida à autora.

\section{REFERÊNCIAS}

ALMEIDA, F. de A. C.; MORAIS, A.M.; CARVALHO, J.M.F.C.; GOUVEIA, J.P.G. Crioconservação de sementes de mamona das variedades nordestina e pernambucana. Revista Brasileira de Engenharia Agrícola e Ambiental, v.6, n.2, p.295-302, 2002.

AMORIM-NETO, M. da S.; ARAÚJO, A.E. de; BELTRÃO, N.E. de M. Clima e solo. In: AZEVEDO, D.M.P. de; LIMA, E.F. (Ed.). O agronegócio da mamona no Brasil. Brasília: Embrapa Informação Tecnológica, 2001. p.6376.

AZEVEDO, D.M.P. de; BELTRÃO, N.E. de M.; BATISTA, F.A.S.; LIMA, E. F. Arranjo de fileiras no consórcio mamona/milho. Campina Grande: Embrapa Algodão, 1997. 21p.

CUCHIARA, C.C.; JUSTO, P.C.; BORGES, C.S.; SILVA, S.D.A.; BOBROWSKI, V.L. Efeito de diferentes con- 
centrações de Boro na germinação in vitro de pólen de mamona (Ricinus communis L.). In: CONGRESSO BRASILEIRO DE MAMONA, 2., 2006, Aracaju, SE. Anais. Aracaju: 2007.

DOMINGUES, E.T; TULMANN NETO, A.; TEÓFILO SOBRINHO, J. Viabilidade do pólen em cultivares de laranja doce. Scientia Agricola,v.56, n.2, p.1999.

FIGUEIREDO NETO, A.; ALMEIDA, F.A.C.; GOUVEIA, J.P.G.; CARNEIRO, R.M.; PEDROZA, J.P. Divergência genética em acessos de mamona (Ricinus communis L.) baseado nas características da semente. Revista de Biologia e Ciências da Terra, v.4, n.2, 2004.

GALETTA, G.J. Pollen and seed management. In: MOORE, J.N.; JANIK, J. (Ed.). Methods in fruit Breeding. Indiana: Purdu University Press, 1983. p.23-47.

GOMES, P.R. Viabilidade e conservação do grão de pólen de cebola (Allium cepa L.). 1998. 54f. Dissertação (Mestrado em Ciência e tecnologia de sementes) - Faculdade de Agronomia "Elizeu Maciel", Universidade Federal de Pelotas, Pelotas.

GOMES, P.R.; RASEIRA, M. do C.B.; BAUDET, L.L.; PESKE, S.T. Armazenamento do grão de pólen de cebola (Allium cepa L.). Revista Brasileira de Sementes, v.25, n.1, p14-17, 2003.

GUERRA, M.; SOUZA, M.J. de. Como observar cromossomos- um guia de técnicas em citogenética vegetal, animal e humana. Ribeirão Preto: Ed. FUNPEC, 2002. 131p.

LOGUERCIO, A.P.; BATTISTIN, A. Microsporogênese de nove acessos de Syzygium cumini (L.) Myrtaceae e oriundos do Rio Grande do Sul- Brasil. Revista da Faculdade de Zootecnia, Veterinária e Agronomia, v.11, n.1. p.192-205, 2004.

LORENZI, H.; MATOS, F.J.A. Plantas medicinais no Brasil: nativas e exóticas. São Paulo: Instituto Plantarum, 2002. 512p.

OLIVEIRA, M. do S.; PADILHA, M.M.M.; KALUME, M.A. de A.Viabilidade de pólen in vivo e in vitro em genótipos de açaizeiro. Acta Botanica Brasílica, v.15, n.1, p.27-33, 2001.

PARTON, R.M.; FISCHER-PARTON, S.; WATAHIKI, M.K.; TREWAVAS, A.J. Dynamics of the apical vesicle accumulation and the rate of growth are related in individual pollen tubes. Journal of Cell Science, n.114, p.2685-2695, 2001.

PEREIRA, R.C.; DAVIDE, L.C.; PATTO RAMALHO, M.A.; ANDRADE, H.B. Alternativas para aumentar a eficiência dos cruzamentos em programas de melhoramento de Eucalyptus. CERNE, v.8, n.2, p.060-069, 2002.

SALOMOM, M.V. Trigo: avaliação de linhagens diplóides obtidas via cultura de anteras. 2003. 180f. Dissertação (Mestrado em Fitotecnia) - Escola Superior de Agricultura "Luiz de Queiroz", Universidade de São Paulo, Piracicaba, 2003.

SANTOS, I.R.I.; SALOMOM, A.M.; MUNDIM, R.C.; RIBEIRO, F.N.S. Criopreservação de eixos embrionários zigóticos de café (Coffe arabica L.). Ministério de Agricultura Pecuária e Abastecimento. Embrapa, 2002.

SAVY FILHO, A. Mamona tecnologia agrícola. Campinas: Ed. EMOPI, 2005. 105p.

SILVA, A.C.T.F.; LEITE, I.C.; BRAZ, L.T. Avaliação da viabilidade do pólen como possível indicativo de tolerância a altas temperaturas em genótipos de tomateiro. Revista Brasileira de Fisiologia Vegetal, v.12, n.2, p.156-165, 2000.

SOUSA-LANG, V. A. de; PINTO, J.E.J. Efeito da concentração de ágar na germinação in vitro do pólen de Araucaria angustifolia (Bert.) O. KTZE. Boletim de Pesquisa Florestal, n.34, p.55-63, 1997.

SOUSA, R.F.; MOTTA, J.D.; GONZAGA, E. da N.; FERNANDES, M.F.; SANTOS, M.J. Aptidão agrícola do assentamento Venâncio Tomé de Araújo para a cultura da Mamona (Ricinus communis - L.). Revista de Biologia e Ciências da Terra, v.4, n.1, 2004.

SOUZA M.M.; PEREIRA, T.N.S.; MARTINS, E.R. Microsporogênese e microgametogênese associadas ao tamanho do botão floral e da antera e viabilidade polínica em maracujazeiro-amarelo (Passiflora edulis Sims f. flavicarpa degener). Ciencia e Agrotecnologia, v.26, n.6, p.1209-1217, 2002.

ZONTA, E.P.; MACHADO, A.A. SANEST - Sistema de análise estatística para microcomputadores. Pelotas, 1984.

Recebido em 29/3/07

Aceito em 27/11/08 